\title{
Enxugando gelo: pirataria e direitos autorais de obras audiovisuais na era das redes
}

\author{
Prof. Carlos Gerbase \\ PPGCOM - FAMECOS - PUCRS
}

\begin{abstract}
Resumo: A circulação digital de obras audiovisuais, tanto de forma "oficial" - quando os detentores dos direitos patrimoniais, autorais e conexos têm, teoricamente, oportunidade de remuneração -, quanto de forma alternativa - a conhecida "pirataria", via internet, ou pela venda de DVDs por vendedores ambulantes - é uma realidade mundial. As campanhas antipirataria, promovidas pelos grandes distribuidores, são cada vez mais agressivas. Ao mesmo tempo, no Brasil, trava-se uma luta jurídica por conta da tentativa de cobrança de direitos autorais referentes às trilhas musicais dos filmes exibidos nas salas de cinema. Este ensaio procura demonstrar que há uma mesma lógica nestes dois enfrentamentos (que repetem fatos acontecidos ainda no século 19, quando da invenção da fotografia) e que esta lógica pouco tem a ver com a situação dos autores.
\end{abstract}

Palavras-chave: direitos autorais, cinema, audiovisual

\begin{abstract}
The digital circulation of audiovisual products, in "official" form - when the owners of the patrimonial, authorial and connected rights have, theoretically, remuneration chance -, and in alternative form - the known "piracy", through Internet, or through ambulant salesmen that sell DVDs - it is a world-wide reality. The campaigns anti-piracy, promoted for the great deliverers, are each time more aggressive. At the same time, in Brazil, there is a legal fight for the collection of referring copyrights to the musical tracks of the films shown in the cinema rooms. This paper looks for to demonstrate that there is one same logic in these two confrontations (that repeat facts happened in century 19, when of the invention of the photograph) and that this logic is far from the the situation of the authors.
\end{abstract}

Key-words: copyrights, cinema, audiovisual

Extracto: La circulación digital de productos audio-visuales, en forma "oficial” - cuando los dueños de las derechas patrimonial, authorial y conectadas tienen, teóricamente, ocasión de la remuneración -, y en la forma alternativa - la "piratería sabida”, a través del Internet, o a través de los vendedores ambulantes que venden DVDs - es una realidad mundial. La contrapiratería de las campañas, promovida para los grandes repartidores, es cada vez más agresiva. Al mismo tiempo, en el Brasil, hay una lucha legal para la colección de referir el copyright a las pistas musicales de las películas demostradas en los cuartos del cine. Este papel busca para demostrar que hay una misma lógica en estas dos confrontaciones (los hechos de esa repetición sucedieron en el siglo 19, cuando de la invención de la fotografía) y que esta lógica está lejos el situación de los autores.

Palabras claves: copyright, cine, audio-visual

\begin{abstract}
Abstrait: La circulation numérique des produits audiovisuels, sous la forme " officielle » - quand les propriétaires des droites patrimoniales, authorial et reliées ont, théoriquement, la chance de rémunération -, et en forme alternative - la «piraterie» connue, par l'Internet, ou par les vendeurs ambulatoires qui vendent DVDs - c'est une réalité mondiale. L'anti-piraterie de campagnes, favorisée pour les grands libérateurs, sont chaque fois plus agressive. En même temps, au Brésil, il y a un combat légal pour la collection de se référer copyright aux voies musicales des films montrés dans les salles de cinéma. Cet article recherche pour démontrer qu'il y a une même logique dans ces deux confrontations (les faits de cette répétition se sont produits en siècle 19, quand de l'invention de la photographie) et que cette logique est loin la de la situation des auteurs.
\end{abstract}

Mots clés: copyright, cinéma, audiovisuel 
O debate jurídico começou em 1976, quando foi inventado o VHS ("Video home system"), primeiro suporte de cópias "ilegais" de filmes em grande escala, e se transferiu para o campo teórico quando a internet ainda dava seus primeiros passos, na década de 1990. A polêmica se popularizou quando a rede atingiu seu estado de circulação global, no final do século passado. E a briga de foice está apenas começando, neste momento (2007) em que as novas e generosas larguras de banda permitem baixar todo tipo de produto audiovisual num tempo inferior a um passeio de carro até a locadora mais próxima.

A realidade se impõe: a distribuição de filmes, vídeos, produtos de TV e demais obras baseadas em imagens em movimento com som sincronizado não é mais a mesma. Na era das redes, os modelos de exploração econômica destes produtos já mudaram. A circulação das obras dá-se, inevitavelmente, em dois planos: o oficial, que ainda funciona da maneira antiga, em que o espectador paga para assistir a um determinado espetáculo; e o alternativo, também conhecido como “pirataria”, em que o espectador atua à margem do sistema e obtém o que quer baixando conteúdos disponíveis na rede, ou comprando uma cópia clandestina num vendedor ambulante, mesmo que estes atos sejam, teoricamente, ilegais.

O governo brasileiro já reconhece a impossibilidade de deter completamente a exploração informal das obras audiovisuais. "Lutar contra a pirataria é um trabalho sem fim, ninguém no governo tem a ilusão de que um dia vai acabar. É como enxugar gelo, mas a gente tem que continuar lutando”, disse Ana Lúcia de Moraes Gomes, secretária executiva do Conselho Nacional de Combate à Pirataria, órgão ligado ao Ministério da Justiça, durante debate sobre pirataria no Festival de Cinema de Gramado de 2007. (Informativo Fundacine - (1), 2007)

Nossa intenção é refletir sobre esse momento, partindo da análise de falácias que costumam permear o debate sobre pirataria e direitos autorais. Também pretendemos comparar alguns modelos que estão sendo apresentados para esse novo cenário tecnológico e cultural, tentando detectar, nos diversos discursos e proposições, os jogos de poder que se escondem sob os argumentos supostamente "legais”. Não acreditamos 
que as soluções para o dilema da circulação de obras audiovisuais na rede sejam técnicas e surjam graças a um novo "software” ou mecanismo de encriptação, a não ser que se atinja - a partir da discussão dessas ferramentas - aquilo que Heidegger chamava de “essência da técnica”, que não é de natureza técnica.

Também não cremos que o campo legal - novas legislações, novas regulamentações -, em que os advogados circulam com tanta desenvoltura, possa dar conta da questão sem que, antes, pensemos nas relações de poder entre o autor, o produtor, o distribuidor, o exibidor e o público, além das mediações tecnológicas (antigas e novas, mas principalmente as novas) que os aproximam e tornam possível a circulação das obras. O embate jurídico do ECAD (Escritório Central de Arrecadação e Distribuição) contra as salas de exibição cinematográficas, uma questão ainda concernente ao modelo antigo de distribuição audiovisual, é um excelente "trailer" do que nos aguarda nos próximos anos. Os jogadores tomam suas posições e começam a mostrar suas cartas.

A primeira falácia (ou blefe) é simples: a preocupação quanto ao direitos autorais é imputada, antes de mais nada, aos próprios autores. Seriam estes os grandes prejudicados com a pirataria, à medida que, numa distribuição ilegal, não recebem os “royalties” da venda de suas obras. Essa afirmação é muito utilizada na argumentação de quem combate a pirataria, pois é muito mais conveniente, do ponto de vista retórico, vitimizar um sujeito, uma pessoa física (o autor da obra), do que uma corporação (que reproduz e distribui a obra).

Na verdade, o cidadão comum não sabe a diferença entre o direito autoral e o direito patrimonial (ou comercial) de um filme. Mas essa diferença é fundamental: enquanto o primeiro se refere a um sujeito que vive (no Brasil, com imensas dificuldades) de sua capacidade criativa, o segundo se refere a empresas, ou conglomerados de empresas, quase sempre de grandes proporções, que lucram - direta ou indiretamente - com a exploração das obras audiovisuais criadas pelos autores. Ao confundir estas duas esferas no âmbito da expressão "direito autoral”, escondem-se os interesses econômicos de maior monta sob a figura do "pobre autor que está sendo 
roubado”. Essa operação funciona há séculos no mundo dos livros, passando depois para a música, para a fotografia, para o cinema e para o audiovisual.

\section{DIREITOS AUTORAIS NA AURORA DA FOTOGRAFIA}

John Tagg, em “El peso da la representación” (2005), conta uma história muito interessante sobre a origem da legislação que trata da propriedade das fotografias. Quando foram obtidas as primeiras imagens permanentes a partir de uma câmara escura, era unânime a opinião de que não havia qualquer direito autoral envolvido com o produto desta tecnologia. Afinal, a transposição efetuada pela máquina fotográfica era de natureza objetiva (a luz incide sobre um determinado motivo da natureza e reflete na direção da lente da câmera, que a leva a um material fotossensível). Não é por coincidência, portanto, que a lente da câmera ainda hoje é chamada de “objetiva”. Um processo mecânico-tecnológico, e não autoral-criativo. Ninguém estava interessado nos direitos autorais referentes a um daguerreótipo, que não permitia a realização de cópias. Nos retratos das famílias burguesas das décadas de 1840, as duas partes estavam satisfeitas: o daguerreotipista, que produzira a imagem e cobrara por ela, e os cidadãos retratados, que pagaram ao daguerreotipista pelo serviço. Também não é coincidência que a grande maioria dessas fotos seja de fotógrafos anônimos. O único nome que ficou para a história foi o de Louis Daguerre, não por seu um grande fotógrafo, e sim por ter inventado o sistema tecnológico, que teve sua patente comprada pelo governo Francês para ser tornada domínio público.

Tudo mudou radicalmente quando foi inventada uma maneira de reproduzir as imagens em massa, criando o mercado dos "cartões-postais”, que tinham, basicamente, três temas, por ordem de importância econômica: pornografia, celebridades da política e das artes, e belas paisagens. Em 1850, a circulação de fotos pornográficas era tão intensa que os habituais guardiões da moralidade aprovaram uma lei que proibia a sua venda em locais públicos e previa penas severas para a posse de negativos com imagens imorais (TAGG, p.137). A participação dos tribunais, contudo, não se restringiu à censura. Com as altas quantias envolvidas na circulação de imagens, era necessário determinar um regime claro de propriedade jurídica das fotos, de modo a impedir o que 
hoje chamamos de "pirataria”. Mas como fazer isso, se uma foto era considerada um registro "objetivo" do mundo, sem envolver um sujeito autoral? Ou, como pergunta Tagg,

Cómo puede una reproducción fotográfica de algo que pertenece a todos - el domínio público de calles, ríos e águas territoriales - reapropiarse de la propiedad pública y devenir propiedad del fotógrafo? Como puede el fotógrafo ser el propietario de la reproducción de lo real, es decir, la fotografia? Estas son las cuestiones que atrajeron la urgente atención de jueces y abogados el na Francia del siglo XIX, a la vez que lidiaban com las categorias legales establecidas y kas concepciones jurídicas de sujeto, realidad e imagen fotográfica (TAGG, p.141).

Tratava-se, antes de mais nada, de assegurar a determinadas empresas distribuidoras de imagens que seus produtos tinham um valor comercial, protegido por lei, impedindo cópias de fotografias já exploradas num determinado mercado e que “pertenciam” a empresas. Mas como conciliar esse desejo de propriedade de uma fotografia se esta não tinha autor algum e não passava de uma transposição do real para um pedaço de papel? E, se não havia um autor-sujeito, como poderia haver um proprietário-empresa? Empresas não apertam o botão de uma câmera e tiram fotos. A “verdade”, em meados do século 19, era que, ao contrário dos sentimentos morais já estabelecidos em relação à pornografia, a pirataria de imagens de belas paisagens ou de seres humanos célebres não tinha nada de errado e, portanto, não podia ser combatida legalmente. O que fazer? Simples: mudar a "verdade”.

Michel Foucault, autor muito presente nas reflexões de Tagg, ensina que a "verdade” sobre determinado assunto depende, basicamente, da hegemonia de determinados discursos sobre outros: “(...) a verdade não existe fora do poder ou sem poder (...). A verdade é deste mundo; ela é produzida nele graças a múltiplias coerções e nele produz efeitos regulamentados de poder.” (FOUCAULT, 2000, p. 12). Na época da invenção da fotografia, a burguesia havia estabelecido o seu "regime de verdade", baseado num certo "regime de sentido" (TAGG, p.136), que, entre outras coisas, permitia o uso de fotografias nos tribunais como provas juridicamente aceitáveis - e, às vezes, muito importantes - nos processos criminais. Essa concepção da fotografia estava totalmente de acordo com o “modo realista” de representação do mundo, que predominava especialmente na literatura. Mais um complicador para as empresas 
distribuidoras de imagem, que tinham que se contrapor a um regime jurídico que dava às fotografias o status de "verdade”. Só havia uma alternativa: atacar essa pretensa objetividade da fotografia e dar-lhe um potencial artístico, capaz de torná-la “propriedade de um sujeito criativo” (TAGG, p. 137).

A lo largo del siglo XIX, la cuestión de si la fotografía pertencia al ámbito del arte o al ámbito de la ciencia era iseparable del proceso de regulación y control de uma pujante industria fotográfica. Alli donde se planteaban custiones relacionadas com los derechos de reproducción, la ley se veía forzada a interceder entre uma defensa que argumentaba que la fotografía no era uns obra de arte y que portanto no podía ser objeto de propiedad restringida, y uma acusación que argumentaba lo contrário. (...) la disputa sobre posición artística de la fotografia se resolvería no em el debate estético, sino em los tribunales. (TAGG, p.137)

O processo de mudança foi bastante rápido, o que não é surpreendente quando forças economicamente poderosas fazem sua pressão no sistema capitalista. Os juristas franceses tiveram que fizeram um esforço enorme para, num contorcionismo legal, permitir que as fotografias fossem objetos de apropriação. Para isso, o fotógrafo deve, necessariamente, passar da categoria de "operador de um processo mecânico e impessoal" para a de "sujeito criador de uma nova realidade a partir da realidade que está à frente da câmera”. Em 1865, o “Code internationale de propriété industrial, artística ett littéraire” determinou que era permissível uma apropriação pessoal de um domínio público (a imagem de uma certa praça de Paris, por exemplo), mas somente com a condição de que esta imagem fotográfica fosse uma criação, e não uma mera reprodução do real

Criava-se, assim, juridicamente falando, a estética fotográfica. Os legisladores começavam o difícil processo de separação das fotos que contém um traço estilístico e estão "revestidas da personalidade de um sujeito criador” (TAGG, p. 141), daquelas que não passam de signos indiciais de uma realidade pretensamente objetiva. A dificuldade, contudo, ficava para o campo da estética, para os debates acadêmicos. Mas, do ponto de vista legal, era simples: um fotógrafo podia "recriar” a realidade, tornando-se assim um “autor”, com certos “direitos autorais”, que eram repassados para as empresas distribuidoras que “zelavam” para que esses direitos não fossem ameaçados. Com isso, 
indiretamente, seus direitos comerciais eram preservados, e a pirataria podia ser juridicamente combatida, com ações da polícia.

A “máquina fotográfica”, antes considerada pela lei um aparelho autônomo, capaz de reproduzir a realidade, transforma-se agora num mero instrumento à disposição de um sujeito disposto a "recriar a realidade" de acordo com seu estilo e suas técnicas particulares. Bastava agora, para completar a operação de transformação da verdade, transformar esse sujeito criativo, individual e humano numa figura jurídica mais adequada para o controle da circulação das imagens. Em 1880, a indústria fotográfica já estava organizada empresarialmente. Nadar, por exemplo, lucrava muito com seus retratos, em sua maioria obtidos em processo coletivo, numa linha de montagem que empregava outros fotógrafos e laboratoristas. Apesar disso, as fotos eram assinadas por Nadar. O empresário, dono do capital capaz de criar e manter o negócio, passava a ser o verdadeiro detentor dos direitos autorais, intelectuais e comerciais das imagens produzidas. Seus empregados não passavam de uma força de trabalho anônima, que vivia de salário. No final das contas, o autor era o capital. É essa a realidade até hoje.

\section{O CINEMA ENTRA EM CENA, SOB AS LEIS DA FOTOGRAFIA}

Quando foi inventado, em 1895, o cinema "naturalmente” seguiu as regras e as leis que a indústria da fotografia estabelecera nada “naturalmente”. Quem lembra os nomes das dezenas de operadores da indústria dos irmãos Lumière? Lembramos apenas dos seus patrões, os empresários Lumière, que detinham o poder econômico. Nos Estados Unidos, Thomas Edison criou, numa velocidade incrível, uma máquina muito bem azeitada de fazer filmes, cuja autoria hoje atribuímos ao próprio Edison, esquecendo das dezenas de operadores de câmera, diretores de arte e montadores que também trabalharam nas películas.

Fue sobre todo em el cine donde la socialización de la indústria produjo la socialización del sujeto-criador y más adelante lá aparición del sujeto colectivo. Sin embargo, fue mediante la aquisición de material de origen literário, productos informativos, etcétera, y sirviéndose com prudência de ese privilegiado instrumento del capitalismo que es el contrato, que tanto la 
"materia prima intelectual" como la "fuerza de trabajo intelectual" del cine fueron monopolizados bajo el control del productor. Desde un principio, los tribunales reconocieron al productor como autor y por tanto propietario de la “creación” producida.” (TAGG, p.148)

Os operadores das câmeras dos irmãos Lumière e de Thomas Edison, portanto, eram obrigados a abrir mão de um possível status de "recriadores da realidade" (base da legislação que tornou possível a propriedade de fotos e, logo depois, dos filmes cinematográficos), para aceitar um contrato de trabalho tradicional, em que eram vistos como mão-de-obra anônima. “En la combinación de la ‘esfera de la creación’ y el ámbito de la producción industrial, la representación legal designaba al ‘sujeto creativo’ como el capital mismo” (TAGG, p.149)

No Brasil contemporâneo, o capital, com toda certeza, não está concentrado nas mãos das empresas produtoras, e muito menos nas dos realizadores dos filmes. O capital está nas mãos dos distribuidores, em sua grande maioria empresas multinacionais, e, em menor escala, dos exibidores. Não é de se estranhar, portanto, que sejam os distribuidores os grandes responsáveis pela campanha de combate à pirataria. A MPA (Motion Pictures Association), que nos Estados Unidos é uma associação de produtores, aqui no Brasil se relaciona basicamente com os distribuidores, nesta e em outras ações voltadas ao mercado. Em seu site, que contém uma seção exclusiva e de grande destaque dedicada à pirataria, há uma frase interessante: “ALL forms of piracy are illegal and carry serious legal consequences.” (Site Oficial da MPA, 2007). A grafia de “ALL”, em caixa alta, serve para estabelecer, com toda a ênfase possível, o que, para a MPA, é a verdade definitiva: a distribuição de produtos audiovisuais em meios não submetidos ao seu controle (ou seja, não regulamentados) é um crime.

Contra essa "verdade" absoluta, que aparentemente tem a seu favor leis nacionais (no Brasil, o Título III do Código Penal, “Dos Crimes Contra a Propriedade Imaterial”, em especial o artigo 184, que trata da violação dos direitos de autor e os que lhe são conexos) e internacionais, começam a surgir algumas contestações. Manoel Almeida, da Revista Consultor Jurídico, (ALMEIDA, 2007), lembra um detalhe muito importante: em todas aquelas advertências que costumamos ler antes de assistir a um filme em DVD, que ameaçam o espectador caso este faça uma cópia do produto em sua 
casa, está sempre omitida a expressão "intuito de lucro”, que a lei, explicitamente, nos parágrafos 1 a 4, considera como condição para que a cópia seja criminosa.

Para Manoel de Almeida, se a lei prevê a penalização apenas quando a cópia é realizada visando ao lucro, direto ou, indireto, então,

Contrario sensu é permitida a cópia integral (grifo do autor) de obra intelectual, sem autorização do detentor do direito autoral, desde que não se vise lucro, seja direto, seja indireto, mas é proibida a cópia não autorizada, mesmo parcial, para fins lucrativos. Assim, não comete crime o indivíduo que compra discos e fitas "piratas", ou faz cópia para uso próprio; ao passo que se o locador o fizer poderão configurar-se violação de direito autoral e concorrência desleal.

Pelo Princípio da Reserva Legal, segundo o qual não há crime sem lei anterior que o defina, nem pena sem prévia fixação legal, a cópia integral não constitui sequer contravenção. No Brasil, quem baixa arquivos pela internet ou adquire produtos piratas em lojas ou de vendedores ambulantes não comete qualquer ato ilícito, pois tais usuários e consumidores não têm intuito de lucro. (ALMEIDA, 2007)

Certamente esta é uma afirmação polêmica, e não faltarão advogados (e dos melhores, contratados pelas distribuidoras internacionais, pelo ECAD e pela MPA) para contestá-la. Mas o simples fato das distribuidoras omitirem um dado específico da lei brasileira já demonstra que um certo “regime de verdade” está sendo construído, a partir de um discurso cuidadosamente articulado. E mais: se a legislação brasileira for modificada, o que parece ser inevitável, com as constantes transformações tecnológicas e a convergência digital, já se prepara um cenário adequado para que estas mudanças atendam, mais uma vez, aos interesses das corporações. E o autor? Esse, como sempre, vai a reboque, pois pode ser precioso na hora de exibir a suposta vítima dos piratas.

\section{OS AUTORES DOS FILMES BRASILEIROS: UMA QUESTÃO DE PODER}

Desde que as salas de cinema “Aeroclube”, da cidade de Salvador, Bahia, foram fechadas durante uma semana, em 2003, por uma ação do ECAD (Escritório Central de Arrecadação e Distribuição), por supostamente sonegarem o pagamento de direitos autorais referentes às trilhas musicais dos filmes apresentados, iniciou-se uma movimentada batalha jurídica que envolve os exibidores, os músicos, o próprio ECAD e 
os produtores dos filmes. O ECAD alega que, segundo a legislação em vigor, todos os cinemas brasileiros devem destinar uma parte da renda bruta de suas bilheterias para o pagamento da exibição pública das músicas que estão na trilha, independente do que os produtores já pagaram pela inclusão (ou “sincronização”, em linguagem técnica) de suas obras nos filmes. Esta sincronização - quase sempre de valor alto, no contexto da média dos orçamentos do cinema brasileiro - é resultado de longas negociações das empresas produtoras com as editoras das respectivas obras musicais e com os produtores fonográficos (no caso de uso de músicas já gravadas).

Além disso, o ECAD fixou em 2,5\% o percentual pela exibição pública. De onde surgiu este número, que não está previsto na Lei de Direitos Autorais vigente? Que tipo de cálculo foi utilizado? Ao que tudo indica, foi o próprio ECAD que decidiu cobrar 2,5\%, em nome dos músicos que diz representar (na verdade, das associações a que os músicos são filiados). Se houve uma negociação para determinar este percentual, quem participou dela, e com que tipo de representação?

Em dezembro de 2003, provavelmente pressionados pelos exibidores, os senadores João Capiberibe (PSB-AP) e Paulo Octávio (PFL-DF) apresentaram o Projeto de Lei $n^{0} 532$, que previa a modificação das normas de pagamento de direitos autorais de trilhas sonoras exibidos em salas de cinema do país. O ECAD então mostrou sua força, levando “indignados” compositores para Senado. Os músicos afirmaram que o projeto de lei era um retrocesso, e a legislação não foi modificada. De 2003 para cá, uma importante rede de cinemas, a LSR (Luís Severiano Ribeiro), fez um acordo com o ECAD e está pagando suas supostas dívidas, enquanto outras preferem contestar a cobrança na justiça.

Não é nossa intenção discutir o processo legal, que vai se arrastar por muitos anos, com argumentos de todas as partes e com todas as filigranas de praxe, e sim procurar, num embate jurídico (na verdade, jurídico-político), as questões de fundo. Por exemplo: o que faz o compositor da trilha sonora de um filme ser considerado um dos seus autores, enquanto o diretor de fotografia, o diretor de arte e o montador não são assim considerados? O advogado Alessandro de Oliveira Amadeu, no artigo "O diretor 
e a autoria da obra cinematográfica”, da Revista de Cinema (agosto de 2007), explica que,

(...) o legislador nacional optou por selecionar e indicar as atuações que seriam elevadas à condição de autores da obra cinematográfica; ou seja, com o intuito de beneficiar um maior número de detentores de direitos intelectuais que atuam nas obras cinematográficas, o legislador, fictamente, escolheu algumas modalidades de autores em detrimento de outras.

Assim, a atual legislação brasileira determina que será considerado autor da obra audiovisual: o autor do argumento literário, o autor do argumento musical/lítero-musical e o diretor, este último sendo o responsável por conferir identidade artística à obra cinematográfica.” (AMADEU, 2007, p. 50)

O que faz o compositor do "argumento lítero-musical” (traduzindo: as músicas e canções que estão na trilha sonora de um filme), o roteirista e o diretor serem considerado “autores”, enquanto o montador e o fotógrafo não são? Cremos que há duas explicações distintas. No caso do roteirista e do diretor, a origem está na famosa política dos autores, um dos pilares mais importantes dos cinemas novos, que, na década de 1960, revolucionaram a concepção estética dos filmes em todo o mundo. Hoje - ao contrário da década de 1940, por exemplo, em que o produtor praticamente assumia a autoria, à medida que mantinha escritores e diretores sob contratos rígidos e decidia o que eles deviam fazer, inclusive do ponto de vista estético - ninguém contesta que roteiro e direção são bases autorais (e não simplesmente “técnicas” ou “instrumentais”) para a criação de um filme. Uma lei que os ignorasse enquanto autores seria considerada ridícula.

Já a inclusão dos músicos, em detrimentos dos fotógrafos e dos montadores na LDA (Lei de Direitos Autorais, de 19 de fevereiro de 1998), em seu segundo capítulo 2, artigo 16, tem uma outra explicação, de base nitidamente "foucaultiana": o poder político e econômico dos músicos, representados pelo ECAD, criou juridicamente a verdade que lhe interessava, da mesma forma que, em meados do século 19, as empresas de produção e distribuição de filmes, com sucessivas ações em tribunais (inclusive de base constitucional), criaram o instituto do "recriador da realidade fotográfica e cinematográfica” para, através da tutela desses direitos, e sua posterior 
transformação em “direitos intelectuais”, transferidos para os empresários, assegurar o êxito de seus negócios.

O ECAD surgiu com base na Lei Federal $n^{\circ} 5.988$ de 1973, que disciplinou a questão dos direitos autorais no Brasil e previu a criação de um escritório central de arrecadação. É uma entidade civil, de natureza privada, que reúne várias associações musicais, como ABRAMUS, AMAR, SBACEM, SICAM, SOCINPRO e UBC, todas também de natureza privada. Para centralizar a arrecadação e a distribuição dos direitos autorais dos músicos filiados a todas estas associações, o ECAD montou uma estrutura que, hoje, segundo o seu próprio "site", é muito poderosa:

Com sede na cidade do Rio de Janeiro, 23 unidades arrecadadoras, 600 funcionários, 84 advogados prestadores de serviço e, aproximadamente, 240 agências autônomas instaladas em todos os Estados da Federação, a instituição possui ampla cobertura em todo o Brasil.

O controle de informações é realizado por um sistema de dados totalmente informatizado e centralizado, que possui cadastrados em seu sistema mais de 214 mil titulares diferentes. Estão catalogadas 795 mil obras, além de 412 mil fonogramas, que contabilizam todas as versões registradas de cada música. Os números envolvidos fazem com que 40 a 50 mil boletos bancários sejam enviados por mês, cobrando os direitos autorais daqueles que utilizam as obras musicais publicamente, os chamados "usuários de música”, que somam mais de 225 mil no cadastro do ECAD. (Site oficial do ECAD, 2007)

Com um exército de 84 advogados prestadores de serviço, o ECAD pode, entre outras coisas, acionar as salas de cinema para defender os interesses dos compositores de trilhas musicais. Não se tem notícia de qualquer ação semelhante movida por roteiristas e diretores, que, segundo a legislação, também poderiam cobrar direitos autorais pela exibição pública de suas obras. Aliás, se os mesmos 2,5\% da bilheteria bruta das salas fossem destinados aos roteiristas e diretores, teríamos $7,5 \%$ da arrecadação comprometida apenas com direitos autorais. Esta parece ser a sugestão dos músicos: que os demais autores criem seus próprios órgãos centrais de arrecadação, à imagem e semelhança do ECAD. O problema é que a atuação do ECAD na defesa de seus associados é bastante polêmica. Há quem o defenda, mas há também - e são muitos - quem o acuse de ineficiência. E, na prática, 7,5\% da bilheteria bruta para os autores 
previstos em lei seria uma fatia incompatível com o que recebe o próprio produtor do filme.

Estamos num impasse: enquanto o ECAD e seus associados querem fazer cumprir a lei, mesmo que a lei seja injusta, os demais autores legais já perceberam que a extensão do mesmo benefício é impossível, conforme parece ter se concluído no encontro que a APACI (Associação Paulista de Cineastas) organizou em São Paulo, no dia 17 de setembro de 2007, na forma de um “Seminário de Direitos Autorais”, com patrocínio das Secretarias da Cultura do Estado e da Cidade de São Paulo, da Secretaria do Audiovisual/MInC e da Cinemateca Brasileira. Uma das resoluções deste encontro, conforme mensagem enviada pelo presidente da APACI, Ícaro Martins:

Devem-se evitar soluções que impliquem a criação de grandes estruturas de arrecadação que, além de caras e contraproducentes para a área audiovisual, tornam-se excessivamente burocráticas, não transparentes, não representativas, repetindo-se erros de outras iniciativas. (Informativo Fundacine (2) 2007)

A resolução faz, obviamente, referência ao ECAD. Ao mesmo tempo, a APACI, a Associação Brasileira de Cineastas (ABRACI-RJ), a Associação dos Roteiristas (AR), e a de Autores de Cinema (AC), prometem constituir de uma sociedade de gestão coletiva de direitos de autor, além de um grupo de trabalho "para debater as questões relativas aos direitos dos autores audiovisuais, com o objetivo de revisar e atualizar a legislação de direitos autorais no Brasil”. (Informativo Fundacine (2) 2007). Presume-se que essa futura e hipotética sociedade não terá a mesma estrutura do ECAD, nem defenderá a atual legislação.

O que coloca diretores, roteiristas, montadores e diretores de fotografia atrás dos compositores da trilha musical na ordem de recebimento dos direitos autorais da exibição pública de um filme é o mesmo mecanismo que coloca certos seres humanos atrás dos porcos na prioridade da escolha de alimentos atirados no lixo, mecanismo bem descrito no curta-metragem "Ilha das Flores”, de Jorge Furtado. Os músicos têm um “dono", o ECAD, que cerca o terreno (estabelecido legalmente por um "título de propriedade”, ou seja, a atual regulamentação dos direitos autorais) em que os dejetos (direitos autorais) são depositados. Os seres humanos (diretores e roteiristas) ficam 
esperando do lado de fora, e consumirão os alimentos que os porcos rejeitarem, SE sobrar alguma coisa.

Ou seja: as diferenças intrínsecas entre porcos e seres humanos não conta, e sim os papéis que eles desempenham na cadeia de relações econômicas do capitalismo. Enquanto roteiristas e diretores não tiverem um "dono" e um "terreno" definido pelo dono, continuarão atrás dos músicos, mesmo que, perante a lei, sejam todos igualmente co-autores de uma obra audiovisual. Em tempo: antes que surja a acusação de que equiparamos maldosamente músicos com porcos, é importante ressaltar que o autor deste ensaio, além de roteirista e diretor de cinema, também é músico (filiado à SICAM, que, por sua vez, é filiada ao ECAD). Para quem viu o filme, cremos que a metáfora está bem clara e não há maldade alguma. Além disso, ao contrário dos porcos de "Ilha das Flores”, o ECAD não está alienado do drama dos diretores e roteiristas, que não recebem seus direitos, ficando do lado de fora da cerca. Pelo contrário: ele sugere que seja criado um novo “dono” e um novo “terreno”, para então se discutir a repartição dos dejetos. Tudo no espírito da lei. Tudo na lógica das relações de poder.

\section{QUESTÕES DE DIREITO, OU QUESTÕES DE COERÇÃO?}

François Ewald, em “Foucault: a norma e o direito” (2000), afirma que

Aquilo a que chamamos direito - em geral - é uma categoria do pensamento que não designa nenhuma essência; se a historicidade pertence ao direito, a procura de uma tal essência é, por princípio, vã. O nome de direito serve para qualificar certas práticas: práticas normativas, práticas da coerção e da sanção social, sem dúvida, prática política certamente, prática da racionalidade também. (p. 160)

A tentativa do ECAD de fechar salas de cinema que não recolhem os direitos autorais da exibição pública das trilhas é um excelente exemplo de coerção social. E, ao mesmo tempo, uma eficiente estratégia para investir o músico como co-autor dos filmes, num "regime de verdade" que tem base jurídica, mas que deve ser sustentado no dia-a-dia, naquilo que Foucalt chama de “microfísica do poder”. Cada notícia de jornal dando conta do "não-pagamento dos direitos autorais aos músicos da trilha” reforça a sua imagem de “verdadeiros” autores. A ausência de notícias semelhantes sobre ações 
de montadores e diretores de fotografia, pouco a pouco, diminui sua possibilidade de pleitear também a co-autoria.

Esse tipo de argumento, de base mais filosófica que jurídica, provavelmente não funcionaria muito bem num tribunal. E um juiz, ao receber a apelação do ECAD, jamais citaria Foucault para indeferir a causa. Mas sempre há espaço para uma discussão mais normativa, a exemplo do que Agnes Heller faz em “Além da justiça” (1998):

A aplicação das mesmas normas e regras a cada um dos membros de um grupo ao qual tais normas e regras se aplicam é um imperativo moral junto com a consistência na aplicação, mesmo não sendo elas de natureza moral. Por outro lado, fazer exceções na aplicação dessas normas e regras é uma ofensa moral, ainda que o assunto não seja de procedência moral. Assim, um ato injusto é moralmente errado por si mesmo, independente do fato de marcar, julgar ou classificar ter algo a ver com a moral daqueles em cuja direção agimos ou a quem classificamos. (p. 23)

Desse ponto de vista, as tentativas do ECAD de cobrar direitos autorais apenas para os músicos, deixando diretores e roteiristas, que fazem parte do mesmo grupo ao qual tais normas e regras se aplicam é uma ofensa moral. O fato de um juiz aceitar a ação (por ser legal) não retira a imoralidade da ação. O argumento do ECAD de que defende apenas aos músicos, e que os outros autores devem cuidar de seus próprios interesses seria o mesmo argumento dos advogados do dono do terreno e dos porcos de "Ilha das Flores": os seres humanos que se virem e arranjem seus próprios advogados. Ou, no pragmático resumo dos diretores de fotografia, tantas vezes pronunciado nos sets quando o microfonista não consegue posicionar o "boom” sem fazer sombra no cenário: “Cada um com seus problemas”.

Agnes Heller vai além:

Não seria justo, pelo bem da simplicidade, considerar-se as normas e regras como certas. Obviamente, elas podem ser questionadas. As normas e regras que constituem um grupo social podem ser claramente injustas, ou seu procedimento ser declarado injusto (o grifo é nosso), mesmo as normas e regras em questão forem consistentemente aplicadas a cada um dos membros do agrupamento. (p.23) 
Aplicando a afirmação de Heller ao nosso dilema: mesmo que diretores e roteiristas também estivessem pleiteando os seus 2,5\% dos direitos autorais pela exibição pública, constituindo assim o agrupamento previsto pela lei, de forma aparentemente aleatória, a ausência do diretor de fotografia e do montador (este o único a manipular imagens e sons num processo essencialmente cinematográfico, e não emprestado de outras linguagens), estaria constituída uma injustiça.

O que acontece, na prática, é que o ECAD - em nome dos compositores, e usando uma estrutura organizacional criada em 1973, hoje detentora de uma força econômica e política considerável - faz, a partir da LDA (1998), o que os roteiristas e diretores não conseguem fazer: pleitear uma fatia considerável das bilheterias cinematográficas, num mecanismo de coerção legal, mesmo que imoral. Como se deu a redação e a aprovação destas leis no Congresso, ou como ela foram regulamentadas e colocadas em prática, são assuntos para os historiadores do poder.

\section{AS NOITES DO "DELETE"}

Na história recente das legislações referentes à atividade audiovisual no Brasil, há dois episódios que se complementam e que permitem mais uma reflexão sobre as práticas do Direito e da Justiça no Brasil. O primeiro aconteceu ainda no governo Fernando Henrique, enquanto o segundo está localizado no governo Lula (no fim do seu primeiro mandato, e já em clima de campanha para o segundo). Nossa fonte para o primeiro episódio é uma entrevista do atual (agosto de 2007) Secretário do Audiovisual do Ministério da Cultura, Orlando Senna, para a revista on-line "Observatório do Direito à Comunicação" (CARVALHO, 2007).

Senna conta que o Gedic (Grupo Executivo de Desenvolvimento da Indústria do Cinema, órgão criado pelo governo FHC) estava articulando a criação de um órgão capaz de regulamentar o setor audiovisual (cinema, TV e novas tecnologias digitais afins). Havia, supostamente, uma grande preocupação do governo para que essa discussão acontecesse em caráter reservado, pois ao mesmo tempo se discutiam, no Congresso e fora dele, outras leis, direta ou indiretamente relacionadas com o 
audiovisual. De acordo com o relato de Senna, tudo foi por água abaixo quando um personagem misterioso apareceu:

Só como anedota, nós temos, na história do cinema brasileiro, o que costumamos chamar de a "Noite do Delete". No último encontro de discussão do Ministro Pedro Parente com o Gedic e seu subgrupo de cineastas (Carlos Diegues, Luiz Carlos Barreto, Luiz Severiano Ribeiro Neto, Rodrigo Saturnino Braga, Evandro Guimarães e Gustavo Dahl, coordenador), quando estava encaminhada a formulação da proposta para a criação de uma Agência do Audiovisual, desceu alguém de um helicóptero e teve uma conversa com o próprio Fernando Henrique. Começaram então uma série de contra-ordens ao pessoal que estava trabalhando na formulação da agência e o próprio ministro Pedro Parente começou a "deletar" tudo o que se referia à televisão. A "noite do delete" ilustra como a coisa era reservada! (SENNA, apud CARVALHO, 2007)

Quem era o passageiro do helicóptero e como ele ficou sabendo o que estava acontecendo nas discussões do GEDIC? Provavelmente nunca ficaremos sabendo. Mas uma coisa podemos supor: ele tinha ligação com as emissoras de TV, e estas não aceitaram dividir com o cinema uma mesma legislação. O resultado é que a tal "Agência do Audiovisual" foi sepultada, para dar lugar a uma Agência Nacional do Cinema (e apenas do Cinema), conhecida hoje como ANCINE.

Com a eleição de Lula, e o sentimento de que havia vontade e força política para finalmente enfrentar os poderosos passageiros de helicópteros, o assunto voltou à pauta. Novas reuniões das entidades, novas discussões, novos projetos de lei. Chegou-se a uma proposta de criação da ANCINAV, que, entre outras coisas, acenava com a modificação de dois artigos da Lei dos Direitos Autorais (o 86 e o 99):

Art. 129. O art. 86 da Lei no 9.610, de 1998, passa a vigorar com a seguinte redação, sendo-lhe acrescidos os parágrafos $1^{\circ}$ e $2^{\circ}$ :

"Art. 86 Os direitos autorais de execução pública das obras audiovisuais serão devidos aos seus titulares pelos responsáveis dos locais ou estabelecimentos a que alude o parágrafo 3o do Art. 68 da Lei n. 9610, de 1998 que as exibirem, pelas emissoras de televisão que as transmitirem e por qualquer outra forma analógica ou digital de comunicá-las ao público.

$\S 1^{\circ}$ Os valores devidos pelos responsáveis pelo pagamento de direitos aos titulares de direitos autorais e conexos das obras audiovisuais não serão superiores a um total correspondente a $1 \%$ (um por cento) da renda bruta, 
menos os impostos, auferida pela exibição das obras audiovisuais e cinematográficas.

$\S 2^{\circ}$ Compete à Ancinav regulamentar a arrecadação e distribuição, em comum, dos direitos relativos à execução pública das obras audiovisuais, inclusive por meio da radiodifusão e transmissão por qualquer modalidade. (NR)"

Art. 130. O art. 99 da Lei no 9.610, de 1998, passa a vigorar com a seguinte redação:

"Art. 99. As associações manterão um único escritório central para a arrecadação e distribuição, em comum, dos direitos relativos à execução pública das obras musicais e lítero-musicais e de fonogramas, excetuadas os direitos relativos à execução pública de obras audiovisuais."

Resumindo: era uma tentativa de estabelecer um percentual de arrecadação de direitos autorais compatível com a realidade do mercado (um por cento para cada coautor previsto em lei, num total de 3\%, e não 7,5\%, como propunha implicitamente o ECAD), e dava à ANCINAV a prerrogativa de regulamentar a arrecadação, afastando o ECAD do processo. Com certeza esta não era a solução do problema, mas era um avanço. O processo de desconstituição das leis que criariam a ANCINAV é mais uma tarefa para os historiadores do poder. Acusada de "stalinista" e "autoritária" (termos amenos, perto de outros que foram usados), por grande parte da imprensa brasileira, o seu o linchamento público foi gradual e certeiro. Depois de poucos meses de debate, sempre pautado pelos grupos hegemônicos do setor de comunicação de massa (e poderíamos colocar o ECAD entre eles), a ANCINAV também teve a sua "noite do delete" e saiu de cena.

É claro que a questão dos direitos autorais é apenas uma parte dos inúmeros problemas que a ANCINAV pretendia enfrentar. Mas, como vimos nos outros exemplos deste ensaio, a indústria audiovisual e seus mecanismos de poder econômico e político estão sempre relacionados com as questões da remuneração da criação artística. Houve, em algum momento, no decorrer da campanha de Lula para o seu segundo mandato, uma acomodação de forças, e o governo decidiu recuar da criação da ANCINAV (e, de tabela, da retirada do ECAD da cobrança de exibição pública de músicas nas salas de cinemas) e acenar para uma futura regulamentação geral do setor de Comunicação, incluindo aí a multibilionária indústria de telecomunicações, que tem segmentos 
tecnologicamente inovadores (telefonia celular e internet), capazes de incomodar, a médio prazo, o mercado tradicional de TV.

Concluímos lembrando que, em todos os casos estudados - que vão desde a criação dos direitos autorais para a fotografia, na França, em meados do século 19, até as recentíssimas "noites do delete" em território brasileiro, passando pela questão da "pirataria" - o debate legal e jurídico nunca aconteceu separado de forças pragmáticas, cotidianas, que atuam em pelo menos três níveis. O primeiro, e mais evidente, é o jogo político e econômico que envolve os poderes Executivo e Legislativo, em especial nas negociações eleitorais. O segundo é a articulação, também muito conhecida, dos discursos da mídia (especialmente a televisão), sempre que as empresas hegemônicas se sentem ameaçadas com alguma regulamentação que julgam nociva.

O terceiro - muito mais sutil, e por isso mais eficiente - é aquele que acontece no campo das "práticas do direito", que se transformam em "práticas de coerção", executadas ao abrigo da lei, mesmo que sejam evidentemente imorais. Estas práticas são criadoras de um "regime de verdade" que vai se impondo e contemplando os interesses da indústria audiovisual, mesmo que tenham sua origem em supostos interesses dos autores, que não passam de coadjuvantes.

É importante lembrar que estas práticas acontecem no próprio campo da legislação, e, portanto, seus efeitos são estratégicos, de médio e longo prazo. Para dar conta destas práticas, é preciso não apenas conhecer a legislação, como também acompanhar algumas ações que tramitam na Justiça brasileira. Como cremos ter demonstrado, a análise crítica e histórica, de cunho acadêmico (e, no nosso caso, de base foucaltiana), permite ver com mais clareza o que tem acontecido na sombra. Em pesquisas futuras, pretendemos abordar outras questões dessa ordem, e em especial o grande desafio imposto pelas novas tecnologias: como o "autor" poderá viver de seu trabalho num mundo em que a circulação de suas obras parece escapar de todas as tentativas de regulamentação, tanto de base técnica, quanto de base legal? 


\section{Notas bibliográficas}

\section{Livros}

AMEDEU, Alessandro de Oliveira. O diretor e a autoria da obra cinematográfica. Revista de Cinema, ano VIII, edição 79, agosto/07. São Paulo: Editora Única, 2007. EWALD, François. Foucault: a norma e o direito. Lisboa: Vega, 2000 FOUCALT, Michel. Microfísica do Poder. Rio de Janeiro: Graal, 2000 HELLER, Agnes. Além da justiça. Rio de Janeiro: Civilização Brasileira, 1998. TAGG, John. El peso de la representación. Barcelona: Editorial Gustavo Gili, 2005

\section{Publicações eletrônicas}

ALMEIDA, Manoel. Tabu pirata: download de filmes e livros para uso privado não é crime. Revista Consultor Jurídico. Disponível em: <conjur.estadao.com.br/static/text/58709,1>. Acesso em: 23 ago. 2007 CARVALHO, Eduardo. A "noite do delete", ou quando a Ancinav reduziu-se a Ancine. Observatório do direito à comunicação. Disponível em:

$<$ www.direitoacomunicacao.org.br/novo/content.php?option=com_content\&task=view \&id=912>. Acesso em: 28 ago. 2007.

ECAD - A instituição. Site oficial do ECAD (Escritório Central de Arrecadação e Distribuição). Disponível em:

<www.ecad.org.br/ViewController/publico/conteudo.aspx?codigo=16,>. Acesso em: 22 ago. 2007

Guerra à pirataria reúne exibidores em Gramado. Informativo Fundacine (1).

Disponível em: <www.fundacine.org.br/home.php? vz=200\&vp=985,>. Acesso em: 25 ago. 2007

Direitos autorais no setor audiovisual em debate. Informativo Fundacine (2). Disponível em: <www.fundacine.org.br/home.php?vz=200\&vp=983>. Acesso em: 25 ago. 2007

Anti-piracy. Site oficial da MPAA - Motion Pictures Association. Disponível em: <www.mpaa.org/piracy.asp>. Acesso em: 25 ago. 2007 